\title{
Prostate Specific Antigen Measurement
}

National Cancer Institute

\section{Source}

National Cancer Institute. Prostate Specific Antigen Measurement. NCI Thesaurus. Code C17634.

The determination of the prostate specific antigen present in a sample. 